\title{
The European hernia society groin hernia classication: simple and easy to remember
}

\author{
M. Miserez $\cdot$ J. H. Alexandre $\cdot$ G. Campanelli $\cdot$ F. Corcione $\cdot$ D. Cuccurullo $\cdot$ \\ M. H. Pascual · A. Hoeferlin · A. N. Kingsnorth · V. Mandala · J. P. Palot • \\ V. Schumpelick $\cdot$ R. K. J. Simmermacher $\cdot$ R. Stoppa $\cdot$ J. B. Flament
}

Published online: 19 March 2008

(c) Springer-Verlag 2008

\section{Erratum to: Hernia (2007) 11:113-116 DOI 10.1007/s10029-007-0198-3}

According to the European Hernia Society groin hernia classification a type 3 hernia is larger than 2 fingers and not restricted to $\geq 3$ fingers as now mentioned in the publication. Therefore the text should be read as follows:

As can be seen in Table 2, the size of the hernia orifice is registered as 1 ( $\leq 1$ finger), 2 (1-2 fingers) and 3 (>2 fingers).

The online version of the original article can be found under doi:10.1007/s10029-007-0198-3.

\section{Miserez ( $\square)$}

Department of Abdominal Surgery,

University Hospital Gasthuisberg,

Herestraat 49, 3000 Leuven, Belgium

e-mail: Marc.miserez@uz.kuleuven.ac.be

J. H. Alexandre

Paris, France

G. Campanelli

Department of Surgical Sciences,

Policlinico Hospital IRCCS, University of Milano,

Pad. Beretta Est Via Francesco Sforza, 35, 20122 Milan, Italy

F. Corcione $\cdot$ D. Cuccurullo

Department of General and Laparoscopic Surgery,

Monaldi Hospital, Via Leonardo Bianchi, 80131 Naples, Italy

M. H. Pascual

Department of Surgery,

12 de Octubre University Hospital, Madrid, Spain

\section{A. Hoeferlin}

Katholisches Klinikum Mainz SHK,

Chirurgische Abteilung, Hildegardstr. 2, 55131 Mainz, Germany

\section{A. N. Kingsnorth}

Peninsula Medical School, Level 7,

Derriford Hospital, Plymouth PL6 8DH, UK

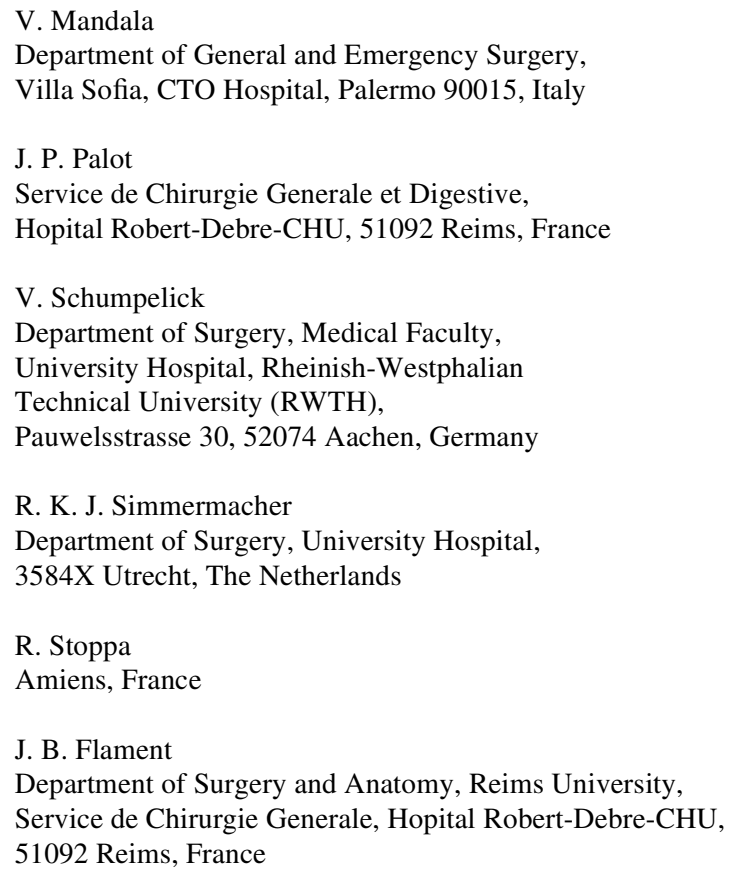

